OPEN ACCESS

Edited by:

Yun-Qing Li,

The Fourth Military Medical

University, China

Reviewed by:

Bing Lang,

University of Aberdeen, UK

Riyi Shi,

Purdue University, USA

*Correspondence:

Shengxi Wu

shengxi@fmmu.edu.cn;

Shucai Ling

lingshucai@zju.edu.cn

Received: 07 May 2016 Accepted: 09 June 2016 Published: 24 June 2016

Citation: Yang J, Chen J, Cai G, Lu R, Sun T, Luo T, Wu S and Ling S (2016) Exposure to Sevoflurane Affects the

Development of Parvalbumin Interneurons in the Main Olfactory

Bulb in Mice.

Front. Neuroanat. 10:72. doi: 10.3389/fnana.2016.00072

\section{Exposure to Sevoflurane Affects the Development of Parvalbumin Interneurons in the Main Olfactory Bulb in Mice}

\author{
Jing Yang ${ }^{1}$, Jing Chen ${ }^{2}$, Guohong Cai ${ }^{3}$, Rui Lu ${ }^{4}$, Tingting Sun ${ }^{1}$, Tingting Luo ${ }^{3}$, \\ Shengxi $W_{u^{3 *}}$ and Shucai Ling ${ }^{1 *}$

\begin{abstract}
${ }^{1}$ Institute of Neuroscience and Anatomy, School of Medicine, Zhejiang University, Hangzhou, China, ${ }^{2}$ Department of Anatomy and K.K. Leung Brain Research Center, Fourth Military Medical University, Xi'an, China, ${ }^{3}$ Department of Neurobiology and Collaborative Innovation Centre for Brain Science, Fourth Military Medical University, Xi'an, China, Medical University, Xi'an, China
\end{abstract} \\ ${ }^{4}$ State Key Laboratory of Military Stomatology, Department of Anesthesiology, School of Stomatology, The Fourth Military
}

Sevoflurane is widely used in adult and pediatric patients during clinical surgeries. Although studies have shown that exposure to sevoflurane impairs solfactory memory after an operation, the neuropathological changes underlying this effect are not clear. This study detected the effect of sevoflurane exposure on the development of calciumbinding proteins-expressing interneurons in the main olfactory bulb (MOB). We exposed neonatal mice to $2 \%$ sevoflurane at two different developmental time points and found that exposing mice to sevoflurane at postnatal day (PD) 7 significantly decreased the expression of GAD67 and parvalbumin (PV) in the olfactory bulb (OB) but did not alter the expression of calretinin (CR) or calbindin D28k (CB). The number and dendritic morphology of $\mathrm{PV}$-expressing interneurons in the $\mathrm{MOB}$ were impaired by exposure to sevoflurane at PD7. However, exposure to sevoflurane at PD10 had no effect on calcium-binding protein expression or the number and dendritic morphology of PVexpressing interneurons in the MOB. These results suggest that exposing neonatal mice to sevoflurane during a critical period of olfactory development affects the development of $\mathrm{PV}$-expressing interneurons in the MOB.

Keywords: sevoflurane, olfactory bulb, PV, CB, CR

\section{INTRODUCTION}

Inhalation anesthetics are widely used in adult and pediatric patients during surgeries, and sevoflurane is one of the most frequently used inhalation anesthetics in infants and children because it has a low blood/gas ratio, low pungency and a rapid onset and recovery (Sakai et al., 2005; Edwards et al., 2010; Gibert et al., 2012). However, animal studies have shown that exposing animals to inhalation anesthetics during critical developmental periods can induce neuropathologic changes and impair cognitive functions (Culley et al., 2003, 2004; Jevtovic-Todorovic et al., 2003; Fredriksson et al., 2007; Rammes et al., 2009). Sevoflurane was shown to induce neuronal

\footnotetext{
Abbreviations: $\mathrm{CB}$, calbindinD28k; CR, calretinin; ECL, chemiluminescence; EPL, external plexiform layer; GABA, $\gamma$-aminobutyric acid; GCL, glomerular cell layer; GL, glomerular layer; MOB, main olfactory bulb; PD, postnatal days; PV, parvalbumin; PVDF, polyvinylidenedifluoride.
} 
apoptosis and neuroinflammation and to inhibit neurogenesis in neonatal mice ( $\mathrm{Lu}$ et al., 2010; Nie et al., 2013; Shen et al., 2013; Zhang et al., 2013). Exposing young rats to sevoflurane altered dendritic spine density during an important stage in synapse formation (Briner et al., 2010). These discoveries indicate that exposure to sevoflurane can affect the normal development of the brain. The olfactory system is vulnerable to volatile agents because its receptors are directly exposed to the outside environment. Although studies have shown that inhaling anesthetic drugs can lead to olfactory dysfunction (Adelman, 1995; Fukumoto et al., 2005), there are few reports showing the neuropathologic changes in olfactory system induced by sevoflurane exposure.

The olfactory system consists of the olfactory epithelium, the main olfactory bulb (MOB) and the olfactory cortex. The MOB is an important part of the olfactory system for olfactory functions. It has high plasticity because its neural network can be modified even by simple stimulation during an olfactory experience, such as exposure to an odorant (Buonviso et al., 1998; Buonviso and Chaput, 2000). The interneurons are the main population of neurons in the MOB, and they are even more sensitive to environmental stimulation because they have a prolonged developmental period and a highly dynamic nature, with continuous genesis occurring during the postnatal and adult periods (Altman, 1969; Lledo et al., 2004). Studies have shown that inducing early postnatal deprivation with uninaris occlusion can decrease the number of granule cells in the MOB and affect their maturation (Frazier-Cierpial and Brunjes, 1989; Brunjes, 1994). Olfactory enrichment can promote the survival of interneurons in the MOB during postnatal development (Mandairon et al., 2008). These discoveries demonstrated that sensory activity is essential for the normal development of interneurons in the MOB. No reports have shown whether inhaling anesthetic drugs affects neurons in the MOB in developing mice. In this study, we aimed to examine the effects of sevoflurane exposure on interneurons in the $\mathrm{MOB}$ of mice at different developmental stages.

Interneurons in the MOB use $\gamma$-aminobutyric acid (GABA) as their main neurotransmitter (Groh et al., 2004) and can be distinguished by their expression of different calciumbinding proteins, such as calretinin (CR), parvalbumin (PV), and calbindin D28k (CB; Parrish-Aungst et al., 2007). The CR-expressing neurons are scattered in the glomerular layer (GL), external plexiform layer (EPL) and granule cell layer (GCL) of the MOB, while $\mathrm{CB}$-expressing neurons are mainly concentrated in the GL (Baimbridge et al., 1982; Hendrickson et al., 1991; Kiraly and Celio, 1991; Kosaka et al., 1995). PVexpressing neurons are mainly located in the EPL (Kosaka et al., 1987, 1994; Crespo et al., 1999; Hwang et al., 2003). These neurons form the main inhibitory circuits in the $\mathrm{MOB}$, and changes in the expression of these calciumbinding proteins can define the functional characteristics of interneurons and impact olfactory functions. To investigate whether sevoflurane exposure during early postnatal life affects the later development of these neurons, we exposed neonatal mice to clinically relevant concentrations of sevoflurane (2\%) for $6 \mathrm{~h}$ as used in the study of Yufune et al. (2016) at two distinct developmental stages in the MOB: postnatal days (PD) 7 and 10. We found that sevoflurane exposure at PD7 decreased the number of PV-expressing neurons and affected their dendritic development. CR- and CB-expressing neurons were not affected by sevoflurane exposure at either PD7 or PD10.

\section{MATERIALS AND METHODS}

\section{Experimental Animals}

C57BL/6 mice were purchased from the Experimental Animal Center of the Fourth Military Medical University and individually housed with free access to food and water in a temperature- and humidity-controlled environment with a 12:12 h light/dark cycle. When the neonatal mice reached PD7 or PD10, the treatments were performed. All experimental procedures received prior approval from the Animal Use and Care Committee for Research and Education of the Fourth Military Medical University (Xi'an, China). Every effort was taken to minimize animal suffering and to reduce the number of animals used. A total of 12 liters containing 102 male offspring were used in this study.

\section{Anesthesia Treatment}

When the pups reached PD7 or PD10, they were randomly divided into a sevoflurane-treated group and an air-treated control group. Mice in the sevoflurane-treated group were placed in a plastic container and continuously exposed to $2 \%$ sevoflurane for $6 \mathrm{~h}$ using air as a carrier with a gas flow of 2 liters/min. During sevoflurane exposure, the container was heated to $38^{\circ} \mathrm{C}$. The control animals were exposed to air without sevoflurane. After $6 \mathrm{~h}$ of treatment, the pups were placed back into their maternal cages.

\section{NissI Staining}

For nissl staining, mice at PD14, PD28 and PD42 in each group were deeply anesthetized with sodium pentobarbital $(50 \mathrm{mg} / \mathrm{kg})$ and then perfused with $20 \mathrm{~mL} 0.01 \mathrm{M}$ phosphate-buffered saline (PBS, $\mathrm{pH}=7.4$ ), followed by $100 \mathrm{~mL} 4 \%$ paraformaldehyde in $0.1 \mathrm{M}$ phosphate buffer solution $(\mathrm{PB}, \mathrm{pH}=7.4)$. Then the Olfactory Bulbs (OB) were removed and post-fixed in the same fixative for $3 \mathrm{~h}$ and then cryoprotected for $24 \mathrm{~h}$ at $4^{\circ} \mathrm{C}$ in $0.1 \mathrm{M}$ $\mathrm{PB}$ containing $30 \%$ sucrose. Coronal sections $(30 \mu \mathrm{m})$ were cut in a freezing microtome (Leica CM1800, Heidelberg, Germany) at $-20^{\circ} \mathrm{C}$ and collected in $0.01 \mathrm{M}$ PBS. For staining, the sections were mounted on gelatin coated glass slides. When dried, the sections were defatted in $75 \%$ ethanol at $37^{\circ} \mathrm{C}$ overnight. Then the sections were stained for $10 \mathrm{~min}$ in $0.1 \%$ cresyl violet solution at RT, after rinsing with water, sections were incubated with $70 \%$ ethanol (3 s), 80\% ethanol (3 s), 90\% ethanol (3 s), 95\% ethanol (3 s), absolute ethanol I (3 s) and absolute ethanol II (5 min) and then with xylene I (10 min) and xylene II (30 min). Sections were observed under an optical microscope after mounting with permount. 


\section{Western Blot Analysis}

When pups reached their ages, they were sacrificed, and the olfactory were rapidly removed. The tissue samples were homogenized using an ultrasonic wave (10 s, 3 times) in RIPA lysis buffer, which contained a cocktail of proteinase and phosphatase inhibitors (Roche). After centrifugation at $12,000 \mathrm{rpm}$ for $15 \mathrm{~min}$ at $4^{\circ} \mathrm{C}$, the protein-containing supernatants were collected. The protein concentrations were determined with a BCA-based kit (Pierce). Lysate samples were subjected to sodium dodecyl sulfate polyacrylamide gel electrophoresis; then, the proteins were transferred onto polyvinylidenedifluoride (PVDF) membranes (Bio-Rad). After blocked with $5 \%$ defatted milk in Tween/Tris-buffered saline (TBST) for $1 \mathrm{~h}$ at room temperature, the membranes were incubated with the primary antibody at $4^{\circ} \mathrm{C}$ overnight. The following primary antibodies were used: mouse monoclonal GAD67 (Chemicon ${ }^{\circledR}$ 1:5000), mouse monoclonal CB (SigmaAldrich 1:1000), goat polyclonal CR (Abcam 1:2000), rabbit polyclonal PV (Abcam 1:1000) and mouse polyclonal $\beta$-actin (Sigma-Aldrich 1:5000). After washing in TBST, the membranes were incubated in a secondary antibody for $2 \mathrm{~h}$ at room temperature. All of the blots were detected by an enhanced chemiluminescence (ECL) detection system (Advansta). The scanned images were quantified with ImageJ (version 1.47) Software.

\section{Immunofluorescence Staining and Cell Counting}

The mice atPD42 in each group were deeply anesthetized with a lethal dose of sodium pentobarbital $(50 \mathrm{mg} / \mathrm{kg}$ of body weight) and then perfused with $0.01 \mathrm{M} \mathrm{PBS}(\mathrm{pH} 7.4$ ), followed by a $4 \%$ phosphate-buffered formalin in a $0.1 \mathrm{M}$ phosphate buffer solution ( $\mathrm{pH} 7.4)$. Coronal olfactory sections $(30 \mu \mathrm{m})$ were cut in a freezing microtome (Leica CM1800, Heidelberg, Germany) at $-20^{\circ} \mathrm{C}$ and collected in $0.01 \mathrm{M}$ PBS. During the staining, the cryostated sections were washed in PBS three times, and following blocking in $10 \%$ normal donkey serum in PBS, the sections were incubated with primary antibodies overnight at $4^{\circ} \mathrm{C}$. The following antibodies were used: mouse monoclonal CB (Sigma-Aldrich 1:500), goat polyclonal CR (Abcam 1:1000), and rabbit polyclonal PV (Abcam 1:500). After rinsing in PBS, the slides were incubated with secondary antibodies conjugated with Alexa Fluor 488 (Invitrogen/Life Technologies 1:500) for $2 \mathrm{~h}$ at room temperature and counterstained with $100 \mathrm{ng} / \mathrm{ml}$ DAPI. After rinsing in PBS, the sections were mounted on gelatin-coated glass slides and cover slipped in Flouromount G. The sections were observed and captured with a confocal laser scanning microscope (Olympus FV1000, Japan). Imaging-ProPlus (LEIKA DMLB) was used to perform quantitative analysis of the positive immunostained cells numbers. Every fourth coronal section through the $\mathrm{OB}$ was collected, and a total of five sections from each mouse were used for quantification. The number of immunostained cells in each field was counted at a higher magnification $(200 \times)$. Three random fields were captured in each section, and the mean number of immunostained neurons per view in the three views was included as the data for each section. The final average number of immunostained neurons per vision in all sections was included as the data for each sample.

\section{Statistic Analysis}

All data were presented as Mean \pm SD. The statistical analysis was performed with GraphPad Prism 5.0 Software (GraphPad Software) and comparisons of the means of two groups were performed using the Student $t$ test. Statistical significance was inferred at $P<0.05$.

\section{RESULTS}

\section{Effects of Sevoflurane Exposure at PD7 and 10 on the Laminar Organization of the MOB}

To explore the effect of sevoflurane exposure on the overall morphology of the MOB, Nissl staining was used to show the structure of the MOB. A distinct laminar organization can be seen in the MOB, with intact glomeruli and clear layers. Following sevoflurane exposure at PD7 and PD10, the organization of the MOB was the same as that in control mice (Figure 1).

\section{Changes in the Expression of GAD67 and Calcium-Binding Proteins in the $\mathrm{OB}$ of Mice Exposed to Sevoflurane at PD7}

To assess the effect of sevoflurane exposure at PD7 on interneurons in the $\mathrm{OB}$ at different developmental stages, we first analyzed GAD67 expression in the OB in the sevofluranetreated mice and control mice at PD14, 28 and 42 using western blot analysis. Compared to the control group, the expression of GAD67 was significantly decreased at PD14, 28 and 42 in the $\mathrm{OB}$ in the sevoflurane-treated mice. The significance of this difference was decreased as the age of the mice increased (Figures 2A,B; $P=0.0001$ at $\mathrm{PD} 14, P=0.000477$ at $\mathrm{PD} 28$, and $P=0.00156$ at $\mathrm{PD} 42$ ). To explore which subtypes of interneurons were affected, the expression of calcium-binding proteins was analyzed using western blot analysis. Compared to control mice, sevoflurane exposure at PD7 significantly decreased the expression of $\mathrm{PV}$ in the $\mathrm{OB}$ of mice when analyzed at PD14, 28 and 42 (Figures 2A,C; $P<0.001$ at PD14 and 28, $P<0.01$ at PD42). However, there were no significant differences in the expression of $\mathrm{CB}$ and $\mathrm{CR}$ between the sevoflurane-treated mice and the control mice (Figures 2A,D,E).

\section{Effects of Sevoflurane Exposure at PD7 on the Number of Calcium-Binding Protein-Expressing Neurons in the MOB}

To determine whether the observed molecular changes represented alterations at the cellular level, immunofluorescence staining was performed to display calcium-binding proteins in immunoreactive (ir) interneurons. The pattern of distribution for PV-ir, CR-ir and CB-ir interneurons were not qualitatively 


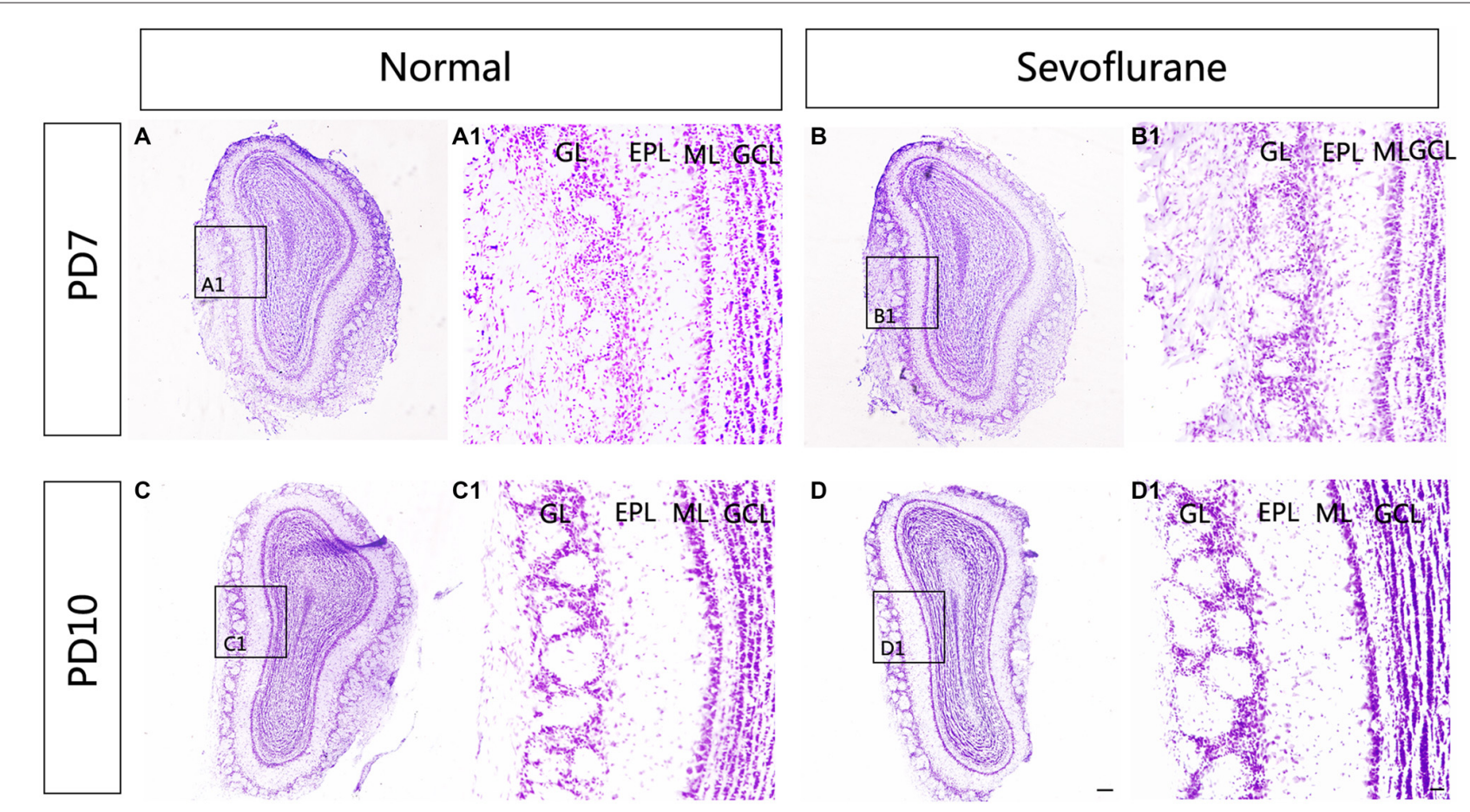

FIGURE 1 | The effect of exposure to sevoflurane at postnatal days 7 (PD7) and 10 (PD10) on the laminar organization of main olfactory bulb (MOB) No significant change in the laminar organization of the MOB was observed between control mice (A) and mice exposed to sevoflurane at PD7 (B). Compared to control MOBs (C), the laminar organization of the MOB in mice that were treated with sevoflurane at PD10 (D) was unchanged. (A1-D1) High magnification images showing the structure of the MOB. Scale bars $=500 \mu \mathrm{m}$ in (D) (applies to A-D) and $100 \mu \mathrm{m}$ in (D1) (applies to A1-D1).

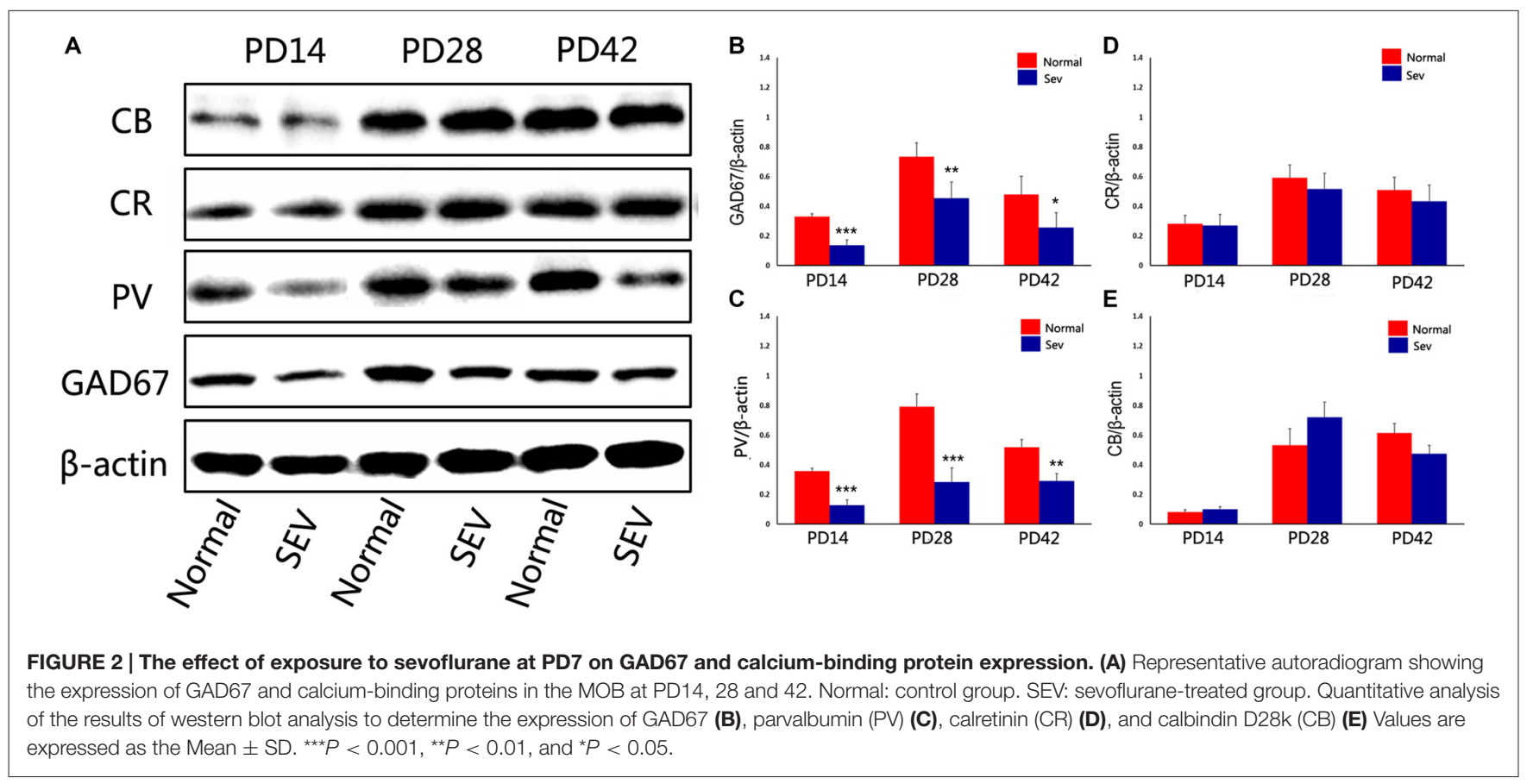

different between sevoflurane-treated mice and control mice. The soma of the PV-ir interneurons were mainly located in the EPL and few PV-ir cells located in ML and IPL. The
CB-ir interneurons were periglomerular interneurons, and the CR-ir interneurons were observed in all layers of the MOB, with the highest packing density in the GL (Figures 3A-F). 


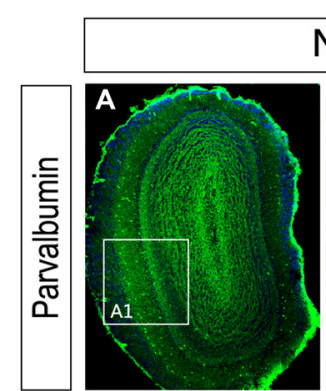

Normal
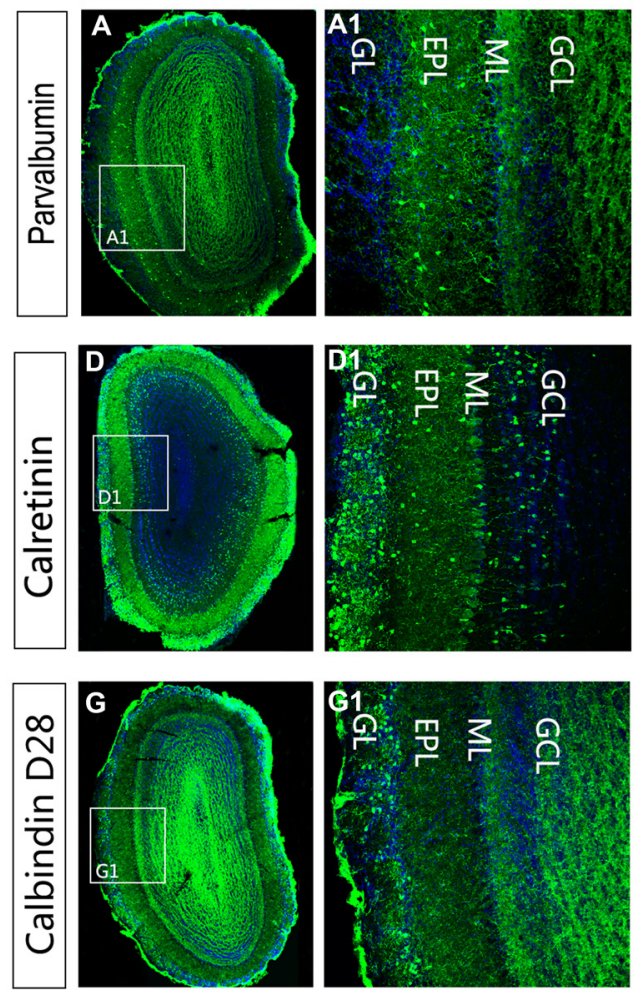

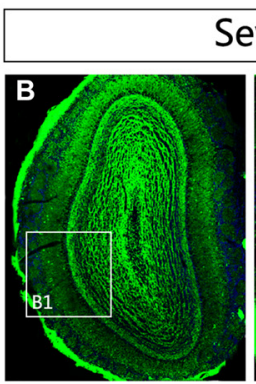

Sevoflurane
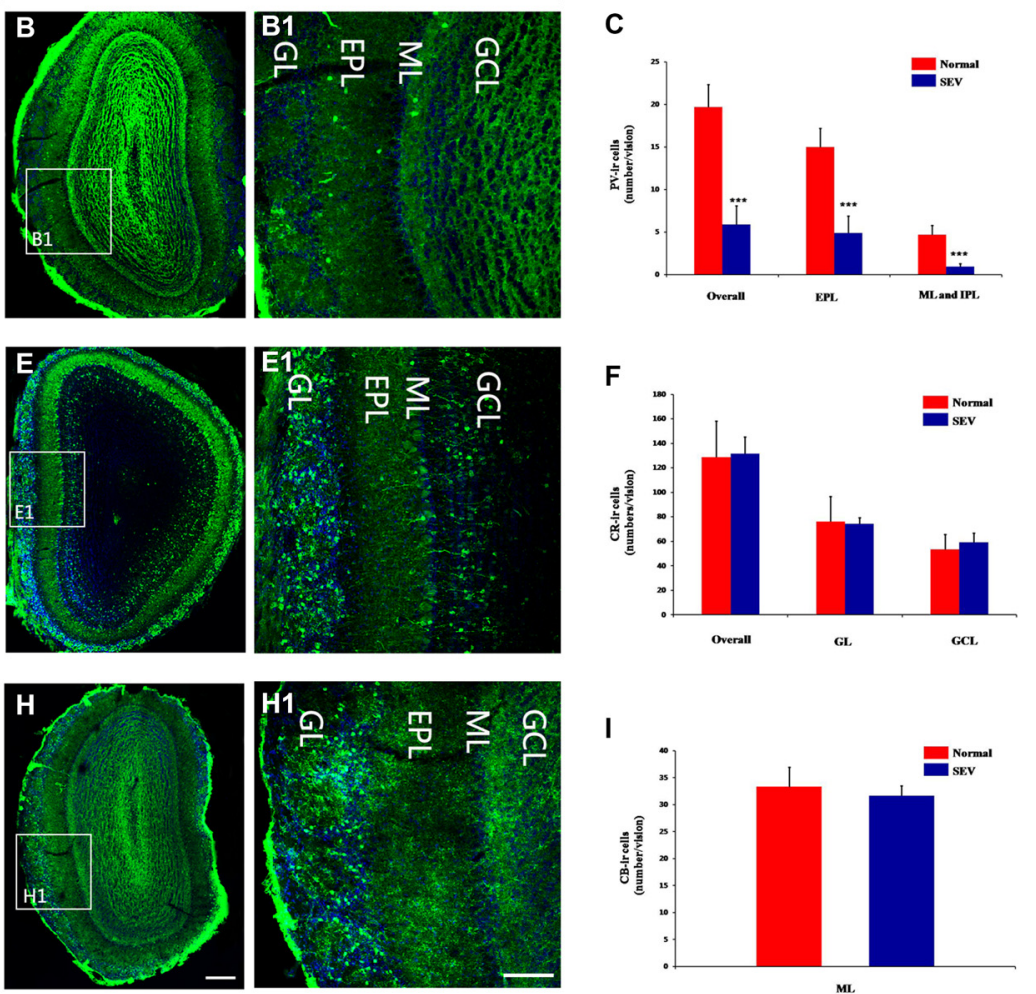

FIGURE 3 | The effect of exposure to sevoflurane at PD7 on the number of calcium-binding protein-expressing neurons in the MOB. Control mice (A) had more PV interneurons in the MOB than the sevoflurane-treated mice (B). (A1,B1) High magnification images of PV interneurons in the MOB. The density of $\mathrm{CR}$ interneurons in the MOB of mice exposed to sevoflurane at PD7 (D) was unaffected compared to the control mice (E). (D1,E1) High magnification images of CR interneurons in the MOB. The density of CB interneurons in the MOB of mice exposed to sevoflurane at PD7 (G) was unaffected compared to the control mice (H). $(\mathbf{G 1}, \mathbf{H 1})$ High magnification images of CB interneurons in the MOB. Normal: control group. SEV: sevoflurane-treated group. Quantification analysis of the number of PV-ir neurons (C), CR-ir neurons (F) and CB-ir neurons (I) in different layers of MOB. Scale bars $=100 \mu \mathrm{m}($ applies to $\mathbf{A}-\mathbf{H}, \mathbf{A 1}-\mathbf{H 1})$. Values are expressed as the Mean \pm SD. ${ }^{\star \star \star} P<0.001$.

Quantitative estimations of PV-ir interneuronal density in the $\mathrm{MOB}$ in PD42 mice revealed that sevoflurane exposure at PD7 significantly decreased the number of PV-ir neurons not only in EPL but also in the ML and IPL (Figure 3G, $P<0.001$ respectively). However, sevoflurane exposure at PD7 did not induce a striking change in the density of CR-ir and $\mathrm{CB}$-ir interneurons compared to their numbers in the controls (Figures 3H,I).

\section{Morphological Alterations in PV-expressing Interneurons in the MOB of Mice Exposed to Sevoflurane at PD7}

To further evaluate the effect of sevoflurane on neuronal morphologies, immunofluorescence staining was used to display the dendritic arbor architecture of these interneurons in control and sevoflurane-exposed mice at PD42. The results showed that the PV-ir interneurons in the $\mathrm{MOB}$ in control mice were multipolar neurons with extensive and clear dendrite complexities with visible secondary and tertiary dendrites
(Figures 4A-B2). In the sevoflurane-treated mice, the dendritic branches of PV-ir interneurons were significantly decreased, and some of these neurons had no dendrites (Figures 4D-D2). Unlike in the PV-expressing neurons, the dendrites of the CR-ir and CB-ir interneurons were not affected by sevoflurane exposure at PD7 (Figures 4E-L).

\section{Effects of Sevoflurane Exposure at PD10 on the Expression of GAD67 and Calcium-Binding Proteins in the OB in Mice}

To further explore the effect of sevoflurane exposure on phases of $\mathrm{OB}$ interneuron development, mice were subjected to sevoflurane exposure at PD10, and the expression of GAD67 and calcium-binding proteinswas detected using western blot analysis. At PD14, 28 and 42, there were no significant differences in the expression of GAD67, PV, $\mathrm{CB}$, and $\mathrm{CR}$ in the $\mathrm{OB}$ between control mice and sevoflurane-exposed mice (Figure 5, $P>0.05)$. 


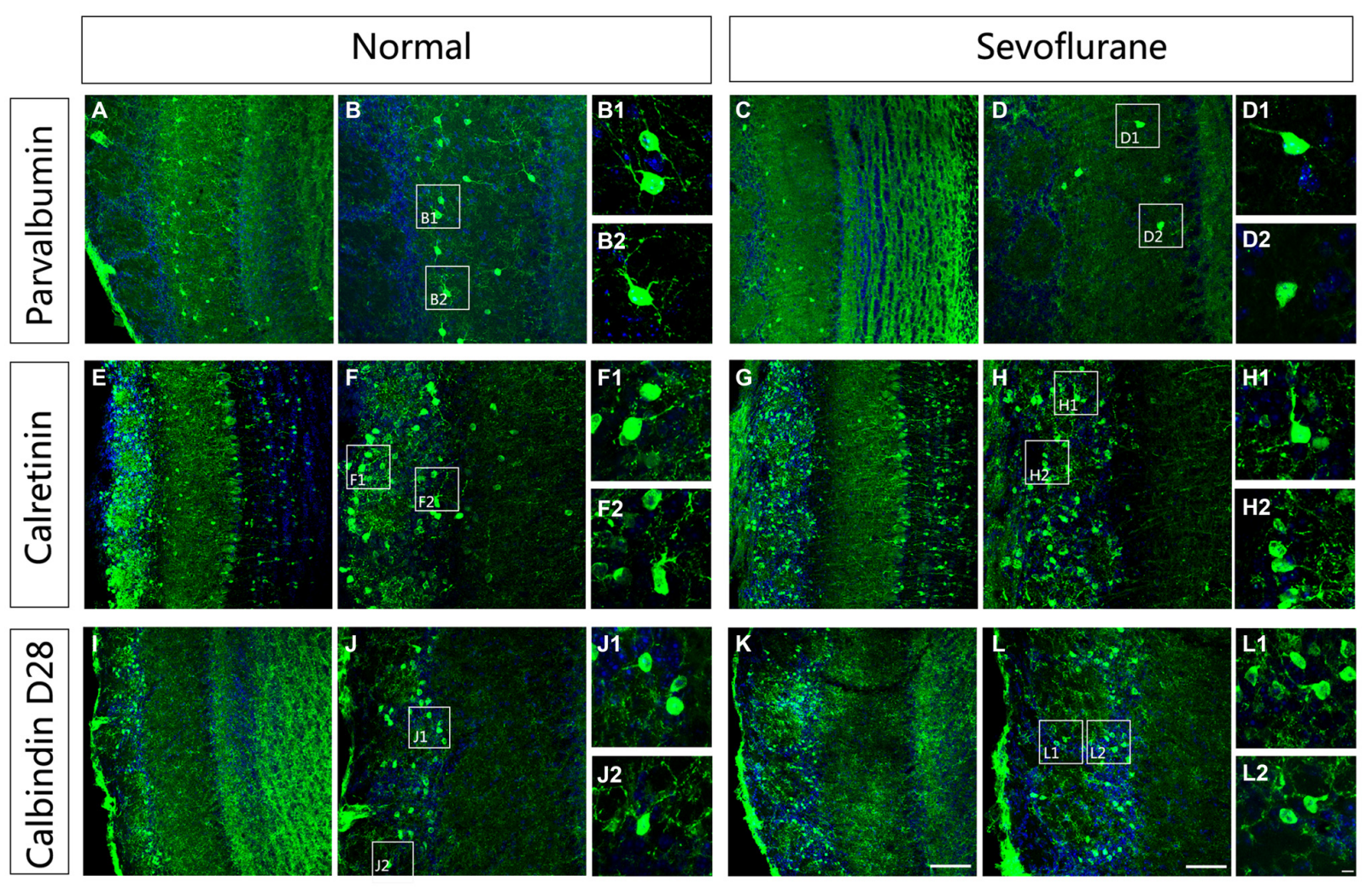

FIGURE 4 | The effect of exposure to sevoflurane at PD7 on the dendritic architecture of calcium-binding protein-expressing neurons in the MOB. Compared to the control group (A,B), the dendritic morphologies of PV interneurons were impaired by exposure to sevoflurane at PD7 (C,D). (B1,B2,D1,D2) High magnification images of $\mathrm{PV}$ interneurons in the MOB. Compared to the control group (E,F), the dendritic morphologies of $\mathrm{CR}$ interneurons were not impaired by exposure to sevoflurane at PD7 (G,H). (F1,F2,H1,H2) High magnification images of CR interneurons in the MOB. Compared to the control group $(\mathbf{I}, \mathbf{J})$, the dendritic morphologies of $C B$ interneurons were not impaired by exposure to sevoflurane at PD7 (K,L). (J1, J2, L1, L2) High magnification images of CR interneurons in the MOB. Scale bars $=100 \mu \mathrm{m}$ in (K) (applies to $\mathbf{A}, \mathbf{C}, \mathbf{E}, \mathbf{G}, \mathbf{I}, \mathbf{K}$ ), $50 \mu \mathrm{m}$ in (L) (applies to $\mathbf{B}, \mathbf{D}, \mathbf{F}, \mathbf{H}, \mathbf{J}, \mathbf{L}$ ), and $5 \mu \mathrm{m}$ in (L2) (applies to $\mathrm{B} 1, \mathrm{~B} 2, \mathrm{D} 1, \mathrm{D} 2, \mathrm{~F} 1, \mathrm{~F} 2, \mathrm{H} 1, \mathrm{H} 2, \mathrm{~J} 1, \mathrm{~J} 2, \mathrm{~L} 1, \mathrm{~L} 2)$.
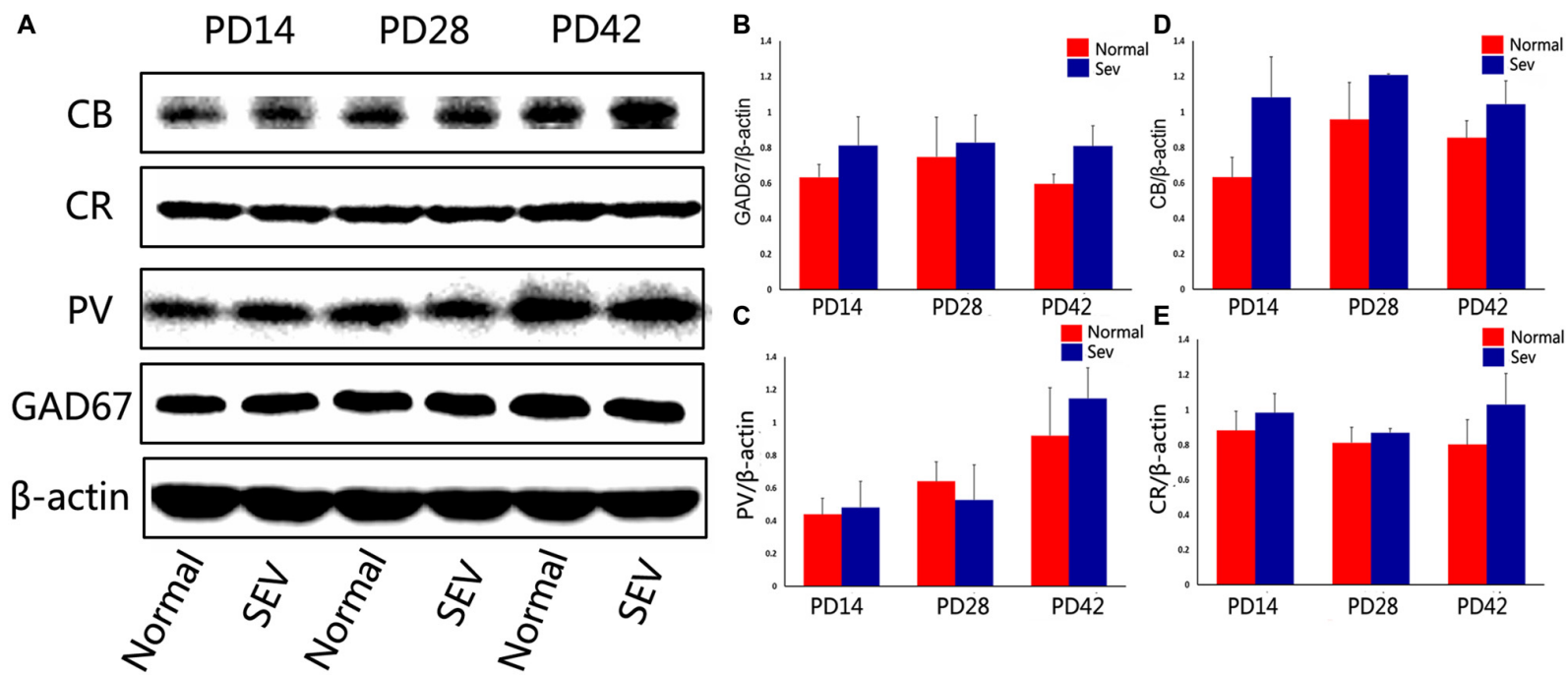

FIGURE 5 | The effect of exposure to sevoflurane at PD10 on GAD67 and calcium-binding protein expression. (A) Representative autoradiogram of GAD67 and calcium-binding protein expression in the MOB at PD14, 28 and 42. Normal: control group. SEV: sevoflurane-treated group. Quantitative analysis of western blot results showing the expression of GAD67 (B), PV (C), CB (D), and CR (E). Values are expressed as the Mean \pm SD. 


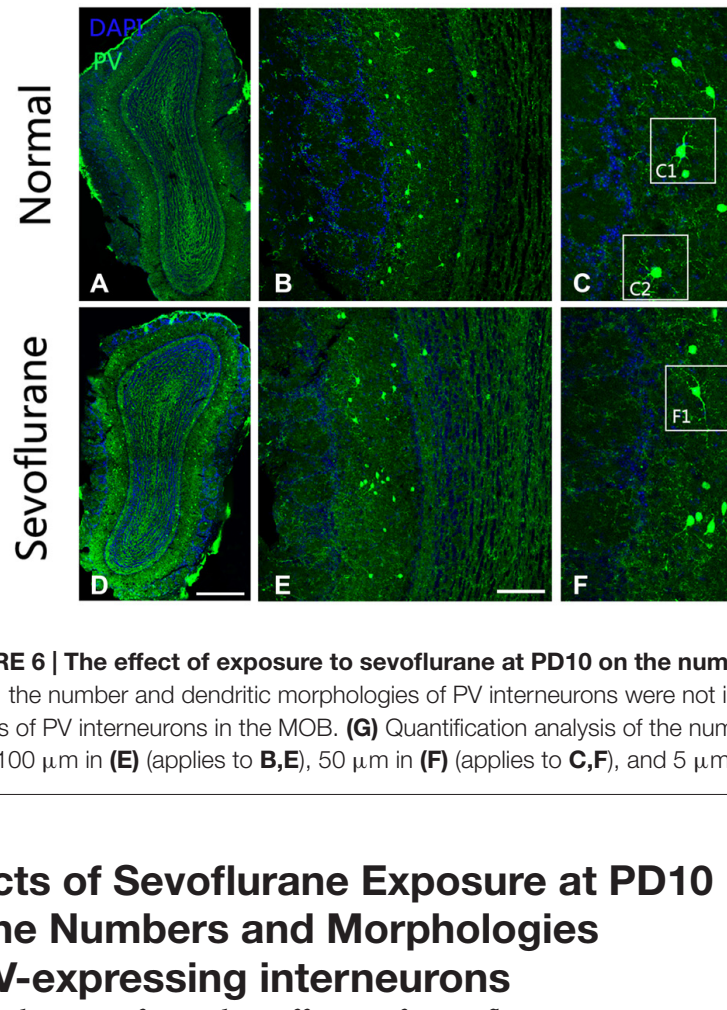

To further confirm the effects of sevoflurane exposure at PD10 on PV-expressing interneurons at the cellular level, immunofluorescence staining was used to detect the numbers and morphologies of PV-ir interneurons in the MOB of control and sevoflurane-treated mice at PD42. No difference was observed in the number of PV-ir interneurons not only in EPL but also in the ML and IPL of the MOB between control mice and sevoflurane-treated mice (Figures 6A,B,D,E,G, $P>0.05)$. The dendrites of the $\mathrm{PV}$-ir neurons in the MOB were clear and ramulose in both the control mice and the sevoflurane-exposed mice (Figures 6C-C2,F-F2). This indicated that sevoflurane exposure at PD10 had no effect on the PVexpressing interneurons of the MOB.

\section{DISCUSSION}

In the present study, by exposing neonatal mice to sevoflurane, we explored the effects of sevoflurane on interneurons in the OB of developing mice. First, we found that the laminar organization of the MOB was not adversely affected by sevoflurane exposure at either PD7 or PD10. Second, sevoflurane exposure at PD7 affected the survival and dendritic development of PV-expressing interneurons in the MOB. Finally, sevoflurane exposure at PD10 had no effect on calcium-binding protein-expressing interneurons in the MOB.

Sevoflurane is one of the most commonly used anesthetics in neonatal and pediatric patients (Lerman et al., 1994). A report showed that the perception of smells was altered during inhalational induction in children (Verschuur et al., 2005). To explore whether sevoflurane exposure during the early neonatal period induces neuropathological changes in the olfactory system for olfactory dysfunctions, the $\mathrm{OB}$ was chosen because it is the first relay station for the transmission of olfactory information and because it is highly plastic. Recent studies have shown that there is a critical developmental period for the mammalian olfactory system (Ma et al., 2014; Tsai and Barnea, 2014). The discoveries of Tsai and Barnea (2014) and Ma et al. (2014) demonstrated that the first postnatal week is the critical period for glomerular map organization in the OB. Meanwhile previous study demonstrated that immature brains are, in general, the most vulnerable to anesthesia at PD7 (Yon et al., 2005). Considering this critical period, we chose two developmental time points that fell within the early postnatal period. We first detected the effects of sevoflurane exposure at PD7 and PD10 on the laminar organization of the MOB at different developmental stages and found that sevoflurane exposure during the early postnatal period did not impair the laminar architecture or volume of the MOB in mice (Figure 1). The clear glomerular structures of the MOB in mice are developed around PD4, and their construction can be affected by olfactory activities (Royal and Key, 1999; Potter et al., 2001; Zou et al., 2004). In some diseases that are associated with olfactory malfunctions, such as schizophrenia, patients display a smaller MOB (Turetsky et al., 2000, 2003). Here, the intact laminar organization of the MOB may indicate that basic olfactory functions are preserved after sevoflurane exposure.

A previous report demonstrated that olfactory acuity was intact in patients after anesthesia with sevoflurane, whereas olfactory memory was impaired (Kostopanagiotou et al., 2011). Although the mechanisms underlying this effect are not understood, previous studies have mainly focused on the effects of sevoflurane on GABAergic circuits (Bein et al., 2008; Michel and Constantin, 2009; Kotani and Akaike, 2013). In the $\mathrm{MOB}$, the ratio of local GABAergic interneurons to excitatory neurons is 100:1(Groh et al., 2004). These interneurons comprise the local circuitry in the MOB. In our study, we found the 
expression of GAD67 was decreased in the OB in mice after sevoflurane exposure at PD7. The most dramatic decrease in its expression was observed at 1 week after sevoflurane exposure. This effect was reduced as the age of the mice increased (Figures 2A,B). In the $\mathrm{MOB}$, most interneurons express GAD67, and GAD67 is expressed in the soma and puncta of neurons, where it is responsible for maintaining baseline levels of GABA (Tsunekawa et al., 2005). The decreased expression of GAD67 might indicate changes in the numbers or functions of interneurons in the MOB. Different subtypes of GABAergic interneurons can be classified by molecular makers, such as CR, PV and CB (Parrish-Aungst et al., 2007). These calcium-binding protein-expressing neurons are the main populations of interneurons in the MOB. The expression of $\mathrm{PV}$ was dramatically reduced in the $\mathrm{OB}$ in the animals exposed to sevoflurane at PD7, and this effect was not reversed as the mice increased in age (Figures 2A,C). Cell counting was performed to determine the number of $\mathrm{PV}$-ir interneurons in the $\mathrm{MOB}$ after sevoflurane inhalation at PD7. The results showed that the number of PV-containing interneurons was significantly decreased of MOB in the sevoflurane-treated mice at later ages (Figures 3A,A1,B,B1,G). However, no changes were observed in the expression of $\mathrm{PV}$ or the number of $\mathrm{PV}$-ir neurons in the mice exposed to sevoflurane at PD10 (Figures 5A-C). It was widely accepted that sevoflurane exposure induced neuronal apoptosis in developing brains (Satomoto et al., 2009; Lu et al., 2010; Fang et al., 2012). A previous study demonstrated that immature brains are, in general, the most vulnerable to anesthesia-induced neuro-apoptosis at PD7 (Yon et al., 2005). Therefore, we concluded that sevoflurane exposure during this critical period of olfactory development affected the survival of $\mathrm{PV}$-expressing interneurons in the MOB.

In humans and rodents, postnatal development is also an important period for the precise formation of neuronal circuits in the central nervous system (Petit et al., 1988; Brown et al., 1997; De Felipe et al., 1997). This postnatal period of immense growth is marked by synaptogenesis, which involves dendritic branching and the formation of synapses (Micheva and Beaulieu, 1996). The study of De Felipe et al. (1997) showed that in the rodent cortex inhibitory synaptogenesis begins at early time, and they find both asymmetrical and symmetrical synapses were present in all layers from P4. Meanwhile, discovery from the development of the adult new-born interneurons showed that GABAergic and glutamatergic synaptic contacts increased at 7 dpi (Panzanelli et al., 2009). Previous studies have shown that exposure to anesthesia during this phase can affect the normal development of spines and synapses (Briner et al., 2010; Lunardi et al., 2010; Amrock et al., 2015). In our study, we found that exposure to sevoflurane at PD7 decreased dendritic branches in PV-ir interneurons in the MOB (Figures 4C,D-D2), whereas sevoflurane exposure at PD10 did not affect dendritic architecture (Figures 6A-F). These results indicate that exposure to sevoflurane during peak synaptogenesis affects the normal development of dendrites in PV neurons in the MOB.

Interneurons in the $\mathrm{OB}$ are a heterogeneous population that is produced beginning in embryogenesis and continuing through adulthood. The development of different calcium- binding protein-expressing neurons occurs in a spatially and temporally regulated manner (Stenman et al., 2003; Waclaw et al., 2006; Young et al., 2007; Batista-Brito et al., 2008; Li et al., 2011). Different interneurons are preferentially produced at different ages. $\mathrm{PV}$-expressing interneurons are produced from late embryogenesis to early postnatal stages (E17 to P3). After $\mathrm{P} 5$, there is no new production of PV-expressing neurons in the OB (Li et al., 2011). Although a previous study showed that after ischemic lesion, progenitors in the SVZ can migrate to the lesion site and differentiate into mature PV-containing neurons, there is no evidence that a lesion in the $\mathrm{OB}$ can induce the regeneration of PV interneurons (Teramoto et al., 2003). This may explain why the loss of PV-expressing interneurons that was induced by sevoflurane exposure at PD7 was not compensated when the mice matured. Unlike PV interneurons, CB- and CR-expressing interneurons can be generated throughout postnatal stages, and CR-expressing interneurons make up the largest proportion of neurons that are born in adult mice (Batista-Brito et al., 2008; Li et al., 2011).In our study, we found that sevoflurane exposure PD7 or PD10 did not affect the number of CB- and CR-expressing interneurons in the MOB (Figures 2A,B,E, 5A,D,E). Previous reports showed that exposing PD4-6 neonatal rats to $1.8 \%$ sevoflurane for $6 \mathrm{~h}$ promoted hippocampal neurogenesis (Chen et al., 2015). Therefore, we assumed that sevoflurane exposure might promote neurogenesis in the $\mathrm{OB}$, and that this may have contributed to fact that there was no change in the number of CB- and CR-expressing interneurons. However, further studies should be performed to test this assumption.

In conclusion, this study is the first to describe the effect of sevoflurane exposure at two different developmental time points on the development of interneurons in the MOB. The results suggest that in neonatal mice, exposure to $2 \%$ sevoflurane of at PD7 can affect the survival and dendritic development of PV-expressing interneurons in the $\mathrm{MOB}$, but it does not affect CB- and CR-expressing interneurons in the MOB. These findings may lay a morphological foundation for studies aimed at determining the effects of sevoflurane exposure on olfactory functions.

\section{AUTHOR CONTRIBUTIONS}

JY designed the experiments and drafted the manuscript. JC and GC participated in the study design and coordination. JY performed the experiments on immunofluorescence and western blotting and analyzed these data with TS. RL performed experiment on animal treatment with anesthesia. TL performed experiment on Nissl staining. SL and SW provided the financial and administrative support for this project. All authors read and approved the final manuscript.

\section{ACKNOWLEDGMENTS}

This work was supported by grants from the National Natural Science Foundation of China (81371404 and 81571243) and Innovation Teams Project in Priority Areas Accredited by the Ministry of Science and Technology of the People's Republic of China (2014RA4029). 


\section{REFERENCES}

Adelman, B. T. (1995). Altered taste and smell after anesthesia: cause and effect? Anesthesiology 83, 647-649. doi: 10.1097/00000542-199509000-00042

Altman, J. (1969). Autoradiographic and histological studies of postnatal neurogenesis. IV. Cell proliferation and migration in the anterior forebrain, with special reference to persisting neurogenesis in the olfactory bulb. J. Comp. Neurol. 137, 433-457. doi: 10.1002/cne.901370404

Amrock, L. G., Starner, M. L., Murphy, K. L., and Baxter, M. G. (2015). Longterm effects of single or multiple neonatal sevoflurane exposures on rat hippocampal ultrastructure. Anesthesiology 122, 87-95. doi: 10.1097/ALN. 0000000000000477

Baimbridge, K. G., Miller, J. J., and Parkes, C. O. (1982). Calcium-binding protein distribution in the rat brain. Brain Res. 239, 519-525. doi: 10.1016/00068993(82)90526-1

Batista-Brito, R., Close, J., Machold, R., and Fishell, G. (2008). The distinct temporal origins of olfactory bulb interneuron subtypes. J. Neurosci. 28, 3966-3975. doi: 10.1523/JNEUROSCI.5625-07.2008

Bein, B., Renner, J., Caliebe, D., Hanss, R., Bauer, M., Fraund, S., et al. (2008). The effects of interrupted or continuous administration of sevoflurane on preconditioning before cardio-pulmonary bypass in coronary artery surgery: comparison with continuous propofol. Anaesthesia 63, 1046-1055. doi: 10. 1111/j.1365-2044.2008.05563.x

Briner, A., De Roo, M., Dayer, A., Muller, D., Habre, W., and Vutskits, L. (2010). Volatile anesthetics rapidly increase dendritic spine density in the rat medial prefrontal cortex during synaptogenesis. Anesthesiology 112, 546-556. doi: 10. 1097/ALN.0b013e3181cd7942

Brown, J. K., Williams, A., Withers, H. R., Ow, K. T., Gramacho, C., Grey, R., et al. (1997). Sources of variability in the determination of micronuclei in irradiated peripheral blood lymphocytes. Mutat. Res. 389, 123-128. doi: 10.1016/s13835718(96)00127-1

Brunjes, P. C. (1994). Unilateral naris closure and olfactory system development. Brain Res. Brain Res. Rev. 19, 146-160. doi: 10.1016/0165-0173(94)90007-8

Buonviso, N., and Chaput, M. (2000). Olfactory experience decreases responsiveness of the olfactory bulb in the adult rat. Neuroscience 95, 325-332. doi: 10.1016/s0306-4522(99)00450-9

Buonviso, N., Gervais, R., Chalansonnet, M., and Chaput, M. (1998). Shortlasting exposure to one odour decreases general reactivity in the olfactory bulb of adult rats. Eur. J. Neurosci. 10, 2472-2475. doi: 10.1046/j.1460-9568.1998. 00266.x

Chen, C., Shen, F. Y., Zhao, X., Zhou, T., Xu, D. J., Wang, Z. R., et al. (2015). Low-dose sevoflurane promotes hippocampal neurogenesis and facilitates the development of dentate gyrus-dependent learning in neonatal rats. ASN Neuro 7:1759091415575845. doi: 10.1177/1759091415575845

Crespo, C., Porteros, A., Arévalo, R., Briñón, J. G., Aijón, J., and Alonso, J. R. (1999). Distribution of parvalbumin immunoreactivity in the brain of the tench (Tinca tinca L., 1758). J. Comp. Neurol. 413, 549-571. doi: 10.1002/(SICI)10969861(19991101)413:4<549::AID-CNE5>3.0.CO;2-D

Culley, D. J., Baxter, M., Yukhananov, R., and Crosby, G. (2003). The memory effects of general anesthesia persist for weeks in young and aged rats. Anesth. Analg. 96, 1004-1009. doi: 10.1213/01.ane.0000052712.67573.12

Culley, D. J., Baxter, M. G., Yukhananov, R., and Crosby, G. (2004). Longterm impairment of acquisition of a spatial memory task following isofluranenitrous oxide anesthesia in rats. Anesthesiology 100, 309-314. doi: 10. 1097/00000542-200402000-00020

De Felipe, J., Marco, P., Fairén, A., and Jones, E. G. (1997). Inhibitory synaptogenesis in mouse somatosensory cortex. Cereb. Cortex 7, 619-634. doi: 10.1093/cercor/7.7.619

Edwards, D. A., Shah, H. P., Cao, W., Gravenstein, N., Seubert, C. N., and Martynyuk, A. E. (2010). Bumetanide alleviates epileptogenic and neurotoxic effects of sevoflurane in neonatal rat brain. Anesthesiology 112, 567-575. doi: 10. 1097/ALN.0b013e3181cf9138

Fang, F., Xue, Z., and Cang, J. (2012). Sevoflurane exposure in 7-day-old rats affects neurogenesis, neurodegeneration and neurocognitive function. Neurosci. Bull. 28, 499-508. doi: 10.1007/s12264-012-1260-4

Frazier-Cierpial, L., and Brunjes, P. C. (1989). Early postnatal cellular proliferation and survival in the olfactory bulb and rostral migratory stream of normal and unilaterally odor-deprived rats. J. Comp. Neurol. 289, 481-492. doi: 10. $1002 /$ cne. 902890312
Fredriksson, A., Pontén, E., Gordh, T., and Eriksson, P. (2007). Neonatal exposure to a combination of N-methyl-D-aspartate and gamma-aminobutyric acid type A receptor anesthetic agents potentiates apoptotic neurodegeneration and persistent behavioral deficits. Anesthesiology 107, 427-436. doi: 10.1097/01. anes.0000278892.62305.9c

Fukumoto, M., Arima, H., Ito, S., Takeuchi, N., and Nakano, H. (2005). Distorted perception of smell by volatile agents facilitated inhalational induction of anesthesia. Paediatr. Anaesth. 15, 98-101. doi: 10.1111/j.1460-9592.2005. 01408.x

Gibert, S., Sabourdin, N., Louvet, N., Moutard, M. L., Piat, V., Guye, M. L., et al. (2012). Epileptogenic effect of sevoflurane: determination of the minimal alveolar concentration of sevoflurane associated with major epileptoid signs in children. Anesthesiology 117, 1253-1261. doi: 10.1097/ALN. 0b013e318273e272

Groh, C., Tautz, J., and Rössler, W. (2004). Synaptic organization in the adult honey bee brain is influenced by brood-temperature control during pupal development. Proc Natl Acad Sci U S A 101, 4268-4273. doi: 10.1073/pnas. 0400773101

Hendrickson, A. E., Van Brederode, J. F., Mulligan, K. A., and Celio, M. R. (1991). Development of the calcium-binding protein parvalbumin and calbindin in monkey striate cortex. J. Comp. Neurol. 307, 626-646. doi: 10.1002/cne. 903070409

Hwang, I. K., Kim, D. S., Lee, H. Y., Lee, J. Y., Choi, G. P., Lee, D. I., et al. (2003). Age-related changes of parvalbumin immunoreactive neurons in the rat main olfactory bulb. Mol. Cells 16, 302-306.

Jevtovic-Todorovic, V., Hartman, R. E., Izumi, Y., Benshoff, N. D., Dikranian, K., Zorumski, C. F., et al. (2003). Early exposure to common anesthetic agents causes widespread neurodegeneration in the developing rat brain and persistent learning deficits. J. Neurosci. 23, 876-882.

Kiraly, E., and Celio, M. R. (1991). Calretinin ontogenesis in the developing DRG of chicken. Acta. Biochim. Biophys. Hung. 26, 95-96.

Kosaka, K., Aika, Y., Toida, K., Heizmann, C. W., Hunziker, W., Jacobowitz, D. M., et al. (1995). Chemically defined neuron groups and their subpopulations in the glomerular layer of the rat main olfactory bulb. Neurosci. Res. 23, 73-88. doi: 10. 1016/0168-0102(95)00930-r

Kosaka, K., Heizmann, C. W., and Kosaka, T. (1994). Calcium-binding protein parvalbumin-immunoreactive neurons in the rat olfactory bulb. 1. Distribution and structural features in adult rat. Exp. Brain Res. 99, 191-204. doi: 10. 1007/bf00239586

Kosaka, T., Kosaka, K., Heizmann, C. W., Nagatsu, I., Wu, J. Y., Yanaihara, N., et al. (1987). An aspect of the organization of the GABAergic system in the rat main olfactory bulb: laminar distribution of immunohistochemically defined subpopulations of GABAergic neurons. Brain Res. 411, 373-378. doi: 10 1016/0006-8993(87)91090-0

Kostopanagiotou, G., Kalimeris, K., Kesidis, K., Matsota, P., Dima, C., Economou, M., et al. (2011). Sevoflurane impairs post-operative olfactory memory but preserves olfactory function. Eur. J. Anaesthesiol. 28, 63-68. doi: 10.1097/EJA. 0b013e328340702b

Kotani, N., and Akaike, N. (2013). The effects of volatile anesthetics on synaptic and extrasynaptic GABA-induced neurotransmission. Brain Res. Bull. 93, 69-79. doi: 10.1016/j.brainresbull.2012.08.001

Lerman, J., Sikich, N., Kleinman, S., and Yentis, S. (1994). The pharmacology of sevoflurane in infants and children. Anesthesiology 80, 814-824. doi: 10 . 1097/00000542-199404000-00014

Li, X., Sun, C., Lin, C., Ma, T., Madhavan, M. C., Campbell, K., et al. (2011). The transcription factor Sp8 is required for the production of parvalbuminexpressing interneurons in the olfactory bulb. J. Neurosci. 31, 8450-8455. doi: 10.1523/JNEUROSCI.0939-11.2011

Lledo, P. M., Saghatelyan, A., and Lemasson, M. (2004). Inhibitory interneurons in the olfactory bulb: from development to function. Neuroscientist 10, 292-303. doi: $10.1177 / 1073858404263460$

Lu, Y., Wu, X., Dong, Y., Xu, Z., Zhang, Y., and Xie, Z. (2010). Anesthetic sevoflurane causes neurotoxicity differently in neonatal naive and Alzheimer disease transgenic mice. Anesthesiology 112, 1404-1416. doi: 10.1097/ALN. 0b013e3181d94de1

Lunardi, N., Ori, C., Erisir, A., and Jevtovic-Todorovic, V. (2010). General anesthesia causes long-lasting disturbances in the ultrastructural properties of developing synapses in young rats. Neurotox. Res. 17, 179-188. doi: 10. $1007 /$ s12640-009-9088-z 
Ma, L., Wu, Y., Qiu, Q., Scheerer, H., Moran, A., and Yu, C. R. (2014). A developmental switch of axon targeting in the continuously regenerating mouse olfactory system. Science 344, 194-197. doi: 10.1126/science.1248805

Mandairon, N., Didier, A., and Linster, C. (2008). Odor enrichment increases interneurons responsiveness in spatially defined regions of the olfactory bulb correlated with perception. Neurobiol. Learn. Mem. 90, 178-184. doi: 10.1016/j. nlm.2008.02.008

Michel, F., and Constantin, J. M. (2009). Sevoflurane inside and outside the operating room. Expert Opin. Pharmacother. 10, 861-873. doi: 10. $1517 / 14656560902798752$

Micheva, K. D., and Beaulieu, C. (1996). Quantitative aspects of synaptogenesis in the rat barrel field cortex with special reference to GABA circuitry. J. Comp. Neurol. 373, 340-354. doi: 10.1002/(SICI)1096-9861(19960923)373: $3<340:$ :AID-CNE3 > 3.0.CO;2-2

Nie, H., Peng, Z., Lao, N., Dong, H., and Xiong, L. (2013). Effects of sevoflurane on self-renewal capacity and differentiation of cultured neural stem cells. Neurochem. Res. 38, 1758-1767. doi: 10.1007/s11064-013-1074-4

Panzanelli, P., Bardy, C., Nissant, A., Pallotto, M., Sassoè-Pognetto, M., Lledo, P. M., et al. (2009). Early synapse formation in developing interneurons of the adult olfactory bulb. J. Neurosci. 29, 15039-15052. doi: 10.1523/JNEUROSCI. 3034-09.2009

Parrish-Aungst, S., Shipley, M. T., Erdelyi, F., Szabo, G., and Puche, A. C. (2007). Quantitative analysis of neuronal diversity in the mouse olfactory bulb. J. Comp. Neurol. 501, 825-836. doi: 10.1002/cne.21205

Petit, T. L., LeBoutillier, J. C., Gregorio, A., and Libstug, H. (1988). The pattern of dendritic development in the cerebral cortex of the rat. Brain Res. 469, 209-219. doi: 10.1016/0165-3806(88)90183-6

Potter, S. M., Zheng, C., Koos, D. S., Feinstein, P., Fraser, S. E., and Mombaerts, P. (2001). Structure and emergence of specific olfactory glomeruli in the mouse. J. Neurosci. 21, 9713-9723.

Rammes, G., Starker, L. K., Haseneder, R., Berkmann, J., Plack, A., Zieglgansberger, W., et al. (2009). Isoflurane anaesthesia reversibly improves cognitive function and long-term potentiation (LTP) via an up-regulation in NMDA receptor 2B subunit expression. Neuropharmacology 56, 626-636. doi: 10.1016/j.neuropharm.2008.11.002

Royal, S. J., and Key, B. (1999). Development of P2 olfactory glomeruli in P2-internal ribosome entry site-tau-LacZ transgenic mice. J. Neurosci. 19, 9856-9864.

Sakai, E. M., Connolly, L. A., and Klauck, J. A. (2005). Inhalation anesthesiology and volatile liquid anesthetics: focus on isoflurane, desflurane and sevoflurane. Pharmacotherapy 25, 1773-1788. doi: 10.1592/phco.2005.25. 12.1773

Satomoto, M., Satoh, Y., Terui, K., Miyao, H., Takishima, K., Ito, M., et al. (2009). Neonatal exposure to sevoflurane induces abnormal social behaviors and deficits in fear conditioning in mice. Anesthesiology 110, 628-637. doi: 10. 1097/ALN.0b013e3181974fa2

Shen, X., Dong, Y., Xu, Z., Wang, H., Miao, C., Soriano, S. G., et al. (2013). Selective anesthesia-induced neuroinflammation in developing mouse brain and cognitive impairment. Anesthesiology 118, 502-515. doi: 10.1097/ALN. ob013e3182834d77

Stenman, J., Toresson, H., and Campbell, K. (2003). Identification of two distinct progenitor populations in the lateral ganglionic eminence: implications for striatal and olfactory bulb neurogenesis. J. Neurosci. 23, 167-174.

Teramoto, T., Qiu, J., Plumier, J. C., and Moskowitz, M. A. (2003). EGF amplifies the replacement of parvalbumin-expressing striatal interneurons after ischemia. J. Clin. Invest. 111, 1125-1132. doi: 10.1172/jci200317170
Tsai, L., and Barnea, G. (2014). A critical period defined by axon-targeting mechanisms in the murine olfactory bulb. Science 344, 197-200. doi: 10. $1126 /$ science. 1248806

Tsunekawa, N., Yanagawa, Y., and Obata, K. (2005). Development of GABAergic neurons from the ventricular zone in the superior colliculus of the mouse. Neurosci. Res. 51, 243-251. doi: 10.1016/j.neures.2004.11.011

Turetsky, B. I., Moberg, P. J., Arnold, S. E., Doty, R. L., and Gur, R. E. (2003). Low olfactory bulb volume in first-degree relatives of patients with schizophrenia. Am. J. Psychiatry 160, 703-708. doi: 10.1176/appi.ajp.160.4.703

Turetsky, B. I., Moberg, P. J., Yousem, D. M., Doty, R. L., Arnold, S. E., and Gur, R. E. (2000). Reduced olfactory bulb volume in patients with schizophrenia. Am. J. Psychiatry 157, 828-830. doi: 10.1176/appi.ajp.157.5.828

Verschuur, M., Jellema, A., Bladbjerg, E. M., Feskens, E. J. M., Mensink, R. P., Moller, L., et al. (2005). The plasminogen activator inhibitor-1 (PAI-1) promoter haplotype is related to PAI-1 plasma concentrations in lean individuals. Atherosclerosis 181, 275-284. doi: 10.1016/j.atherosclerosis.2005. 01.036

Waclaw, R. R., Allen, Z. J. II, Bell, S. M., Erdelyi, F., Szabo, G., Potter, S. S., et al. (2006). The zinc finger transcription factor Sp8 regulates the generation and diversity of olfactory bulb interneurons. Neuron 49, 503-516. doi: 10.1016/j. neuron.2006.01.018

Yon, J. H., Daniel-Johnson, J., Carter, L. B., and Jevtovic-Todorovic, V. (2005). Anesthesia induces neuronal cell death in the developing rat brain via the intrinsic and extrinsic apoptotic pathways. Neuroscience 135, 815-827. doi: 10 . 1016/j.neuroscience.2005.03.064

Young, K. M., Fogarty, M., Kessaris, N., and Richardson, W. D. (2007). Subventricular zone stem cells are heterogeneous with respect to their embryonic origins and neurogenic fates in the adult olfactory bulb. J. Neurosci. 27, 8286-8296. doi: 10.1523/jneurosci.0476-07.2007

Yufune, S., Satoh, Y., Akai, R., Yoshinaga, Y., Kobayashi, Y., Endo, S., et al. (2016). Suppression of ERK phosphorylation through oxidative stress is involved in the mechanism underlying sevoflurane-induced toxicity in the developing brain. Sci. Rep. 6:21859. doi: 10.1038/srep21859

Zhang, Y., Dong, Y., Zheng, H., Shie, V., Wang, H., Busscher, J. J., et al. (2013). Sevoflurane inhibits neurogenesis and the Wnt-catenin signaling pathway in mouse neural progenitor cells. Curr. Mol. Med. 13, 1446-1454. doi: 10. 2174/15665240113139990073

Zou, D. J., Feinstein, P., Rivers, A. L., Mathews, G. A., Kim, A., Greer, C. A., et al. (2004). Postnatal refinement of peripheral olfactory projections. Science 304, 1976-1979. doi: 10.1126/science. 1093468

Conflict of Interest Statement: The authors declare that the research was conducted in the absence of any commercial or financial relationships that could be construed as a potential conflict of interest.

The handling Editor declared a shared affiliation, though no other collaboration, with several of the authors JC, GC, RL, TL and SW and states that the process nevertheless met the standards of a fair and objective review.

Copyright (C) 2016 Yang, Chen, Cai, Lu, Sun, Luo, Wu and Ling. This is an openaccess article distributed under the terms of the Creative Commons Attribution License (CC BY). The use, distribution and reproduction in other forums is permitted, provided the original author(s) or licensor are credited and that the original publication in this journal is cited, in accordance with accepted academic practice. No use, distribution or reproduction is permitted which does not comply with these terms. 